\title{
ANÁLISE DAS CONDIÇÕES DE ACESSIBILIDADE NA ONG CAINE (CENTRO DE APOIO E INTEGRAÇÃO DE PORTADORES DE NECESSIDADES ESPECIAIS) EM JABOATÃO DOS GUARARAPES-PE
}

\author{
SILVA, Kamila Cavalcanti (1); \\ SILVA, Sunamita Maria da (2) \\ (1)UFPE, Graduanda em Arquitetura e Urbanismo \\ e-mail: kamila.cavalcanti.s@gmail.com \\ (2)UFPE, graduanda em Arquitetura e Urbanismo \\ e-mail: sunamitasilva17@gmail.com
}

\begin{abstract}
RESUMO
Pernambuco tem cerca de 2.426.106 pessoas (27,58\%) com pelo menos uma das deficiências investigadas pelo CENSO 2010, sendo visual, auditiva, motora e mental ou intelectual. Em Jaboatão dos Guararapes o sistema de saúde formou parcerias com instituições não governamentais especializadas em acessibilidade que cedem suas estruturas físicas e alguns profissionais que trabalham junto a profissionais das secretarias de saúde e assistentes sociais para tratar de pessoas com deficiência. Este artigo analisa a qualidade espacial em relação à acessibilidade de uma dessas instituições não governamentais do município de Jaboatão dos Guararapes em Pernambuco.
\end{abstract}

Palavras chave: arquitetura; acessibilidade; ambiente construído.

\begin{abstract}
Pernambuco has about 2,426,106 people (27.58\%) with at least one of the deficiencies investigated by CENSO 2010 being visual, auditory, motor and mental or intellectual. In Jaboatão dos Guararapes, the health system has formed partnerships with non-governmental institutions specialized in accessibility that yield their physical structures and some professionals that work with health and social care professionals to treat people with disabilities. This article analyzes a spatial quality in relation to the accessibility of one or more non-governmental institutions of the municipality of Jaboatão dos Guararapes in Pernambuco.
\end{abstract}

Keywords: Architecture; Accessibility; Built Environment.

\section{METODOLOGIA}

A metodologia do presente artigo consiste em analisar as questões dimensionais, de sinalização e organizacionais do espaço, comparando os ambientes construídos em relação a NBR 9050, que desde 2004 estabelece critérios e parâmetros técnicos aplicáveis a projeto, construção, instalação e adaptação de edificações, mobiliário, espaços e 


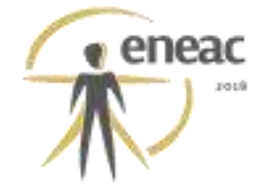

equipamentos urbanos às condições de acessibilidade (ABNT, 2014). Foram realizados registros fotográficos, medições e conversas com os usuários e funcionários a fim de comparar se as características citadas anteriormente estão obedecendo aos parâmetros estabelecidos na NBR 9050 atualizada em 2015.

Em um primeiro momento analisaremos o percurso que os pacientes da ONG realizam todos os dias para chegarem ao local, analisamos desde as calçadas até as paradas de ônibus procurando saber se há ou não dificuldades antes mesmo de chegar ao local. No momento seguinte analisamos o acesso imediato ao local como os parâmetros das escadas e rampas existentes no local e por fim analisamos o programa do local, discutimos itens como as áreas das salas, as larguras das circulações e os itens que compõe o programa de necessidades da ONG analisada.

\section{O CASO DAONG CAINE}

A ONG CAINE - Centro de Apoio e Integração de Portadores de Necessidades Especiais surgiu no ano 2000 e vem dando assistência à criança, adolescentes e jovens adultos com necessidades especiais de caráter físico ou mental (congênitas ou adquiridas) e a seus familiares. Através de um atendimento e acompanhamento multidisciplinar visando a habilitação e reabilitação. A sede está localizada na rua Dr. Antônio Carlos de Oliveira, no bairro de candeias, próximo ao supermercado Wallmart em um imóvel de $250 \mathrm{~m}^{2}$.

Segundo a atual coordenadora da ONG, Neide Arcanjo, a instituição tem capacidade para 200 atendimentos ao mês. Destes, hoje, cerca de $80 \%$ são para crianças com autismo, TDH, síndrome de Down e paralisia cerebral. Para tal, o CAINE dispõe de 22 funcionários sendo 4 funcionários fixos e os demais profissionais da saúde e assistente sociais que se reversam para proporcionar atendimento psicológico, fonoaudiologia, terapia ocupacional, fisioterapia, psicopedagogia, neuro psicopedagogia, psiquiatria e serviço social. Este último abrange seus trabalhos com os familiares uma vez por semana em atendimento grupal (Figura 1).

Figura 1 - Sala para atendimento familiar

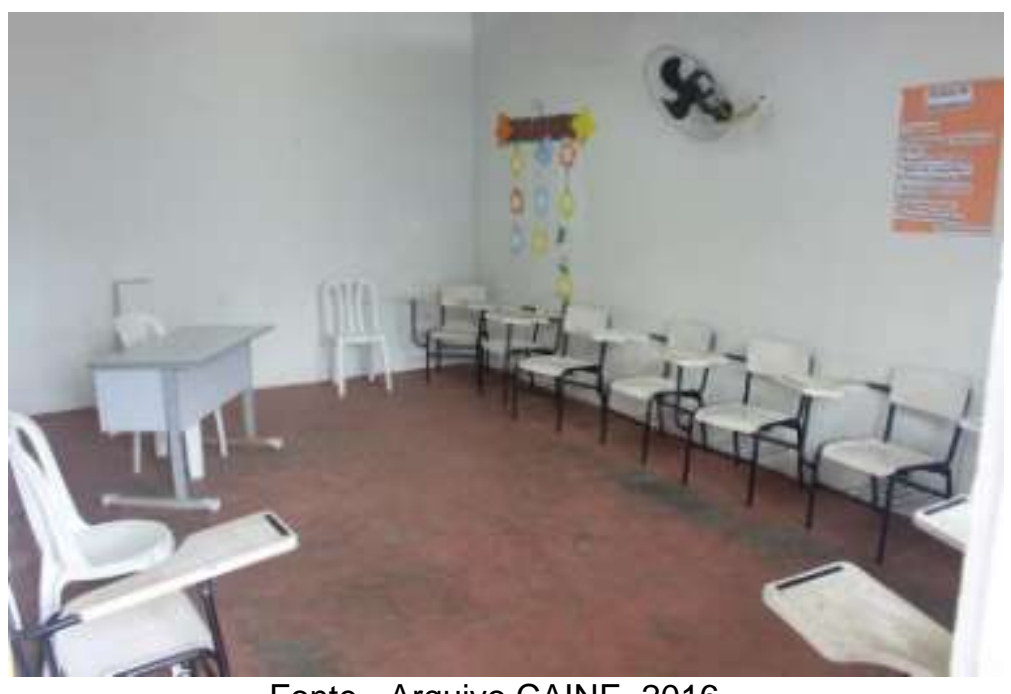

Fonte - Arquivo CAINE, 2016

É um fato inegável que dentro de uma sociedade a deficiência e mesmo a diferença pode gerar estranhamento e conflito, começando pelo núcleo familiar. Mesmo a pessoa com necessidades especiais recebendo tratamento de um ou mais profissionais da saúde, não 


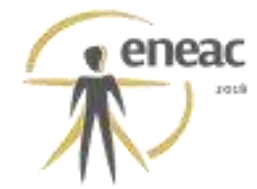

isenta de forma nenhuma a responsabilidade da família tem sobre o individuo no quesito de desenvolvimento das atividades do dia a dia tornando-o o mais funcional possível somando a isso também, uma sensibilidade mais apurada sobre o estado psicológico.

A discussão colocada em pauta brevemente nesse parágrafo é que mesmo diagnosticada a doença na gestação o convívio e os cuidados são descobertos aos poucos, trazendo a necessidade de não só do portador de necessidades especiais, mas sua família também receberem algum tipo de assistência, transformando a ONG CAINE completa em relação aos serviços oferecidos, mas sua estrutura possui várias falhas no quesito acessibilidade como veremos a seguir.

\section{A AVALIAÇÃO ESPACIAL E DA ACESSIBILIDADE DO AMBIENTE CONSTRUIDO E SEU ENTORNO.}

\subsection{Avaliação da acessibilidade e mobilidade do entorno}

Segundo a atual coordenadora do CAINE, quase a totalidade dos usuários da instituição chegam ao local através de transportes públicos.

O percurso das paradas de ônibus mais próximas até o CAINE (Figura 2) pode se tornar um grande desafio. Estes pontos de ônibus, com estruturas precárias, onde não proporcionam sombra, abrigo para intempéries ou assentos para a espera. Da parada norte-sul para a travessia da pista não existe nenhuma faixa de pedestres, sinalização rebaixamento da calçada que facilite a travessia. Os desafios continuam tanto para quem vem do sentido norte como do sul, pois as calçadas nem sempre encontram-se nas dimensões e materiais adequados e em grande parte do percurso encontram-se obstruídas por árvores e objetos colocados de forma inapropriada no percurso.

\section{Figura 2 - Vista aérea do terreno}

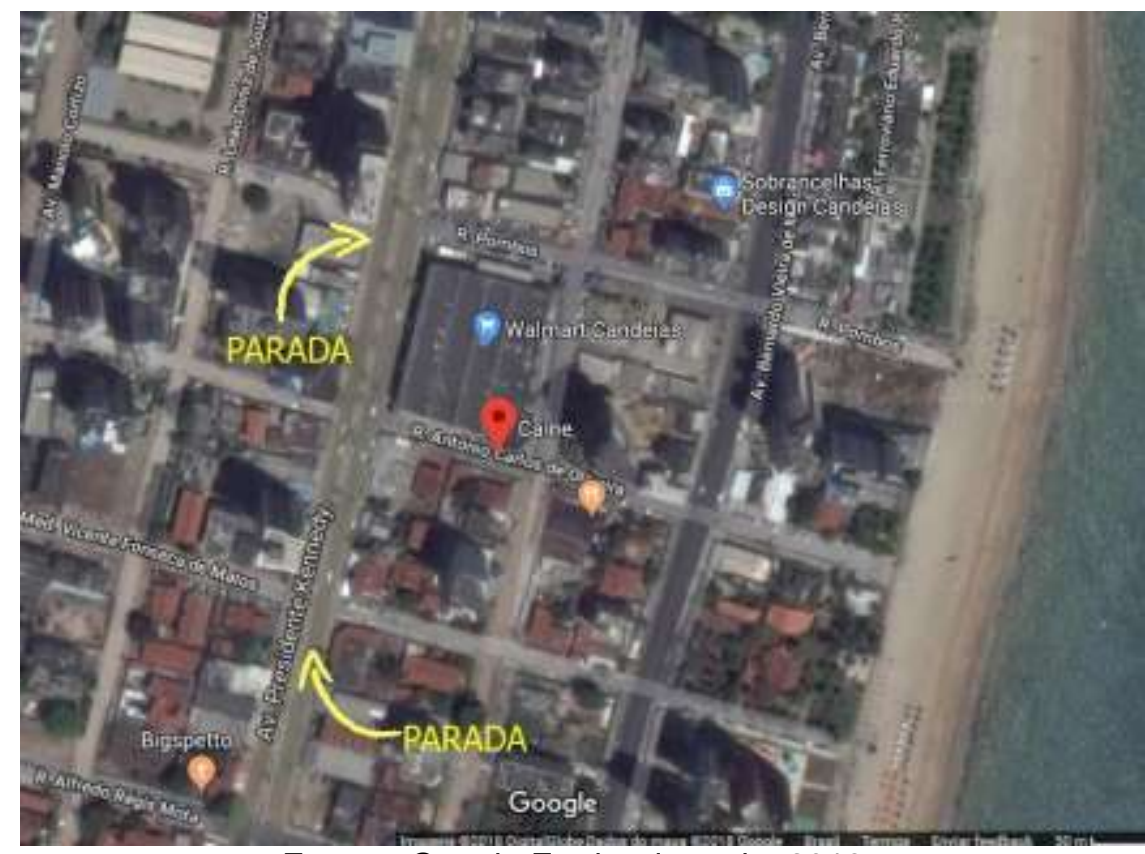

Fonte - Google Earth adaptada, 2018. 


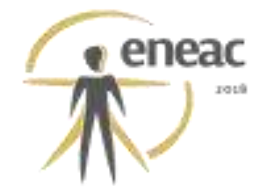

O esquema, encontrado na imagem abaixo (Figura 3) representa um modelo calçada/via/calçada acessível que permite a qualquer pessoa com mobilidade reduzida a livre circulação pelo local, o processo que adequação do acesso a ONG pode ser vinculado prefeitura do município de Jaboatão dos Guararapes.

Figura 3 - Esquema de faixa elevada para travessia

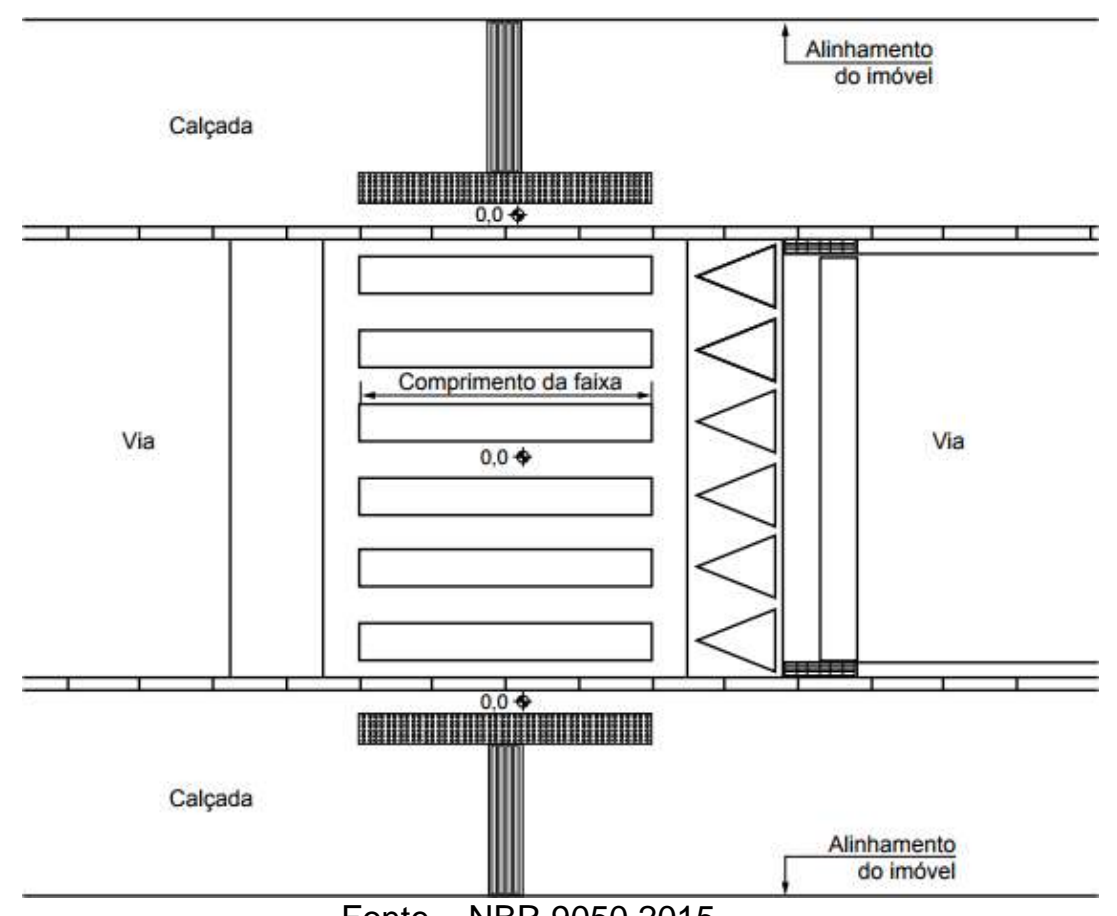

Figura 4 - Captura de trecho do percurso

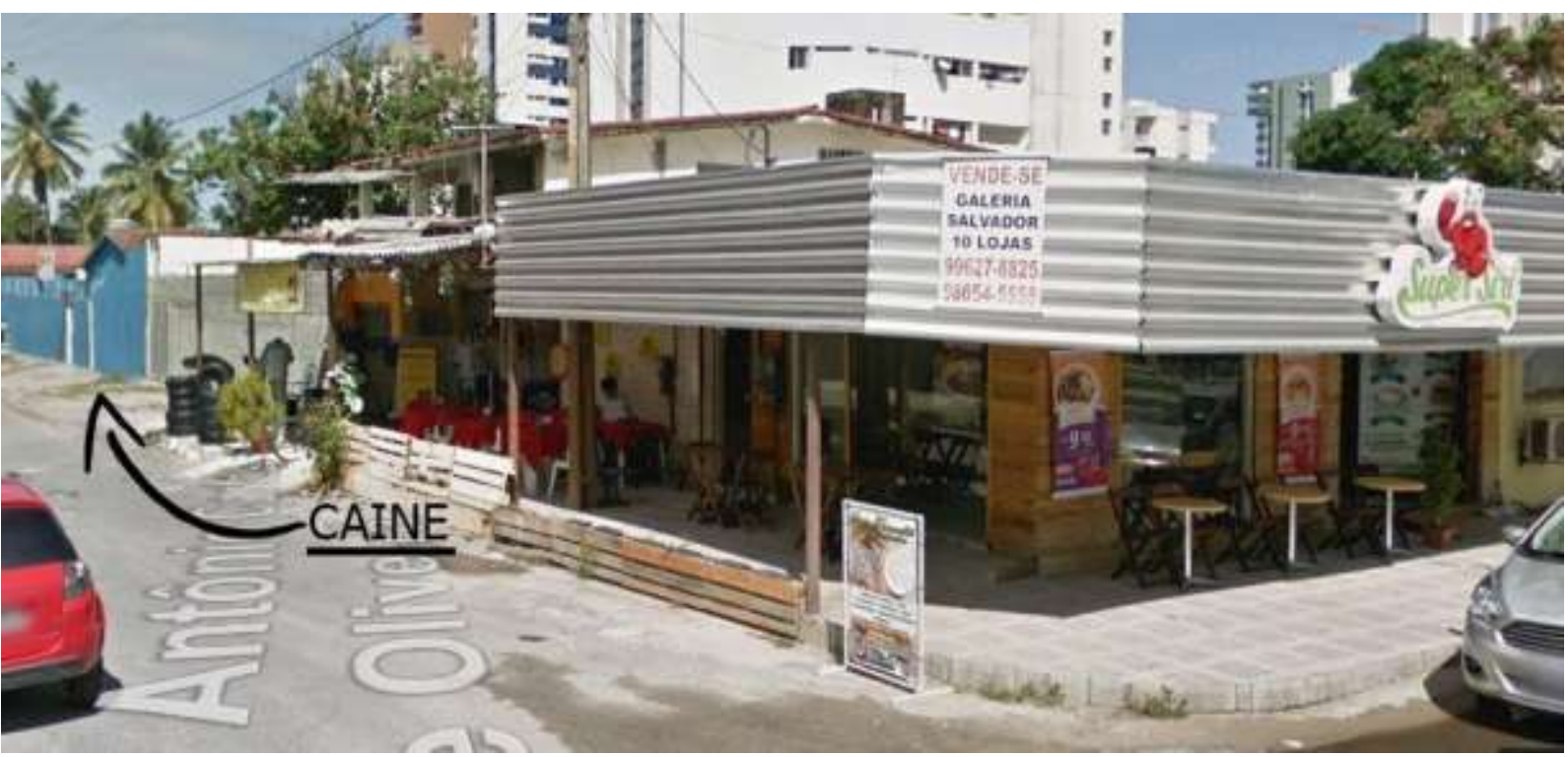

Fonte - Google Street View adaptada, 2018. 


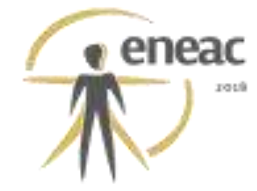

Imagem 5 - vista geral da edificação/ Modelo ideal de rampas
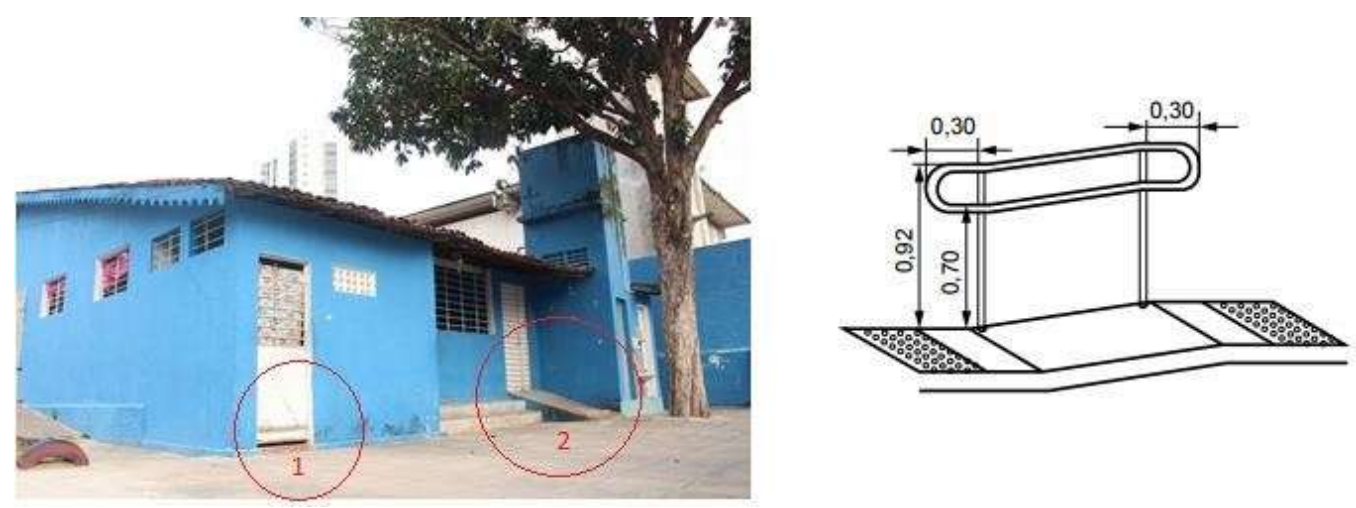

Fonte - Arquivo CAINE, 2016/ NBR 9050.

O principal acesso a recepção não possui nenhum elemento acessível e a única forma de chegar até a recepção é através de degraus (que não obedecem a norma) ou através das rampas laterais e travessar diversos ambientes.

A falha na acessibilidade é apresentada logo na entrada da ONG representados na foto (Imagem 5), como o desnível na porta para a copa (1) e a falta de sinalização e a ausência do guarda corpo na única rampa existente na entrada principal (2) a rampa em questão não tem a largura mínima de 1,2 metros, não possui inclinação máxima de 8,33\% e o piso da rampa não é de um material antiderrapante como é recomendado pela NBR 9050.

\subsection{Avaliação dos setores e ambientes internos}

Nota-se que o acesso aos ambientes internos é dificultado pois a ausência de piso tátil alerta ou direcional que possibilite a orientação, principalmente, às pessoas com dificuldade visual. $E$ que as portas e aberturas não possuem maçanetas, barras antipânico ou puxadores adequados. A questão da sinalização também é bem preocupante pois não há nenhuma das sinalizações de acordo com a norma brasileira de acessibilidade (tabela 1) na edificação analisada.

Tabela 1 - Aplicação e formas de informação e sinalização

\begin{tabular}{|c|c|c|c|c|c|}
\hline \multirow{2}{*}{ Aplicaçäo } & \multirow{2}{*}{ Instalaçăo } & \multirow{2}{*}{ Categoria } & \multicolumn{3}{|c|}{ Tipos } \\
\hline & & & Visual & Tátil & Sonora \\
\hline \multirow{4}{*}{$\begin{array}{l}\text { Edificaçăo/ } \\
\text { espaço/ } \\
\text { equipamentos }\end{array}$} & \multirow{2}{*}{ Permanente } & $\begin{array}{l}\text { Direcional/ } \\
\text { informativa }\end{array}$ & & & \\
\hline & & Emergência & & & \\
\hline & \multirow{2}{*}{ Temporária } & $\begin{array}{l}\text { Direcional/ } \\
\text { informativa }\end{array}$ & & & \\
\hline & & Emergencia & & & \\
\hline \multirow{2}{*}{ Mobiliários } & Permanente & Informativa & & & \\
\hline & Temporária & Informativa & & & \\
\hline
\end{tabular}

Fonte - NBR 9050, 2015 


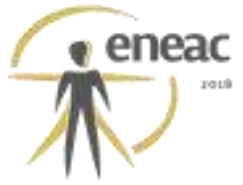

A edificação (Figura 6) comporta um programa composto por 10 salas de atendimento no setor da saúde, uma grande área de recreação assistida chamada tatame, recepção, uma sala de terapia familiar, um grande pátio e áreas administrativas.

\section{Figura 6 - Planta Baixa com esquema de setorização}

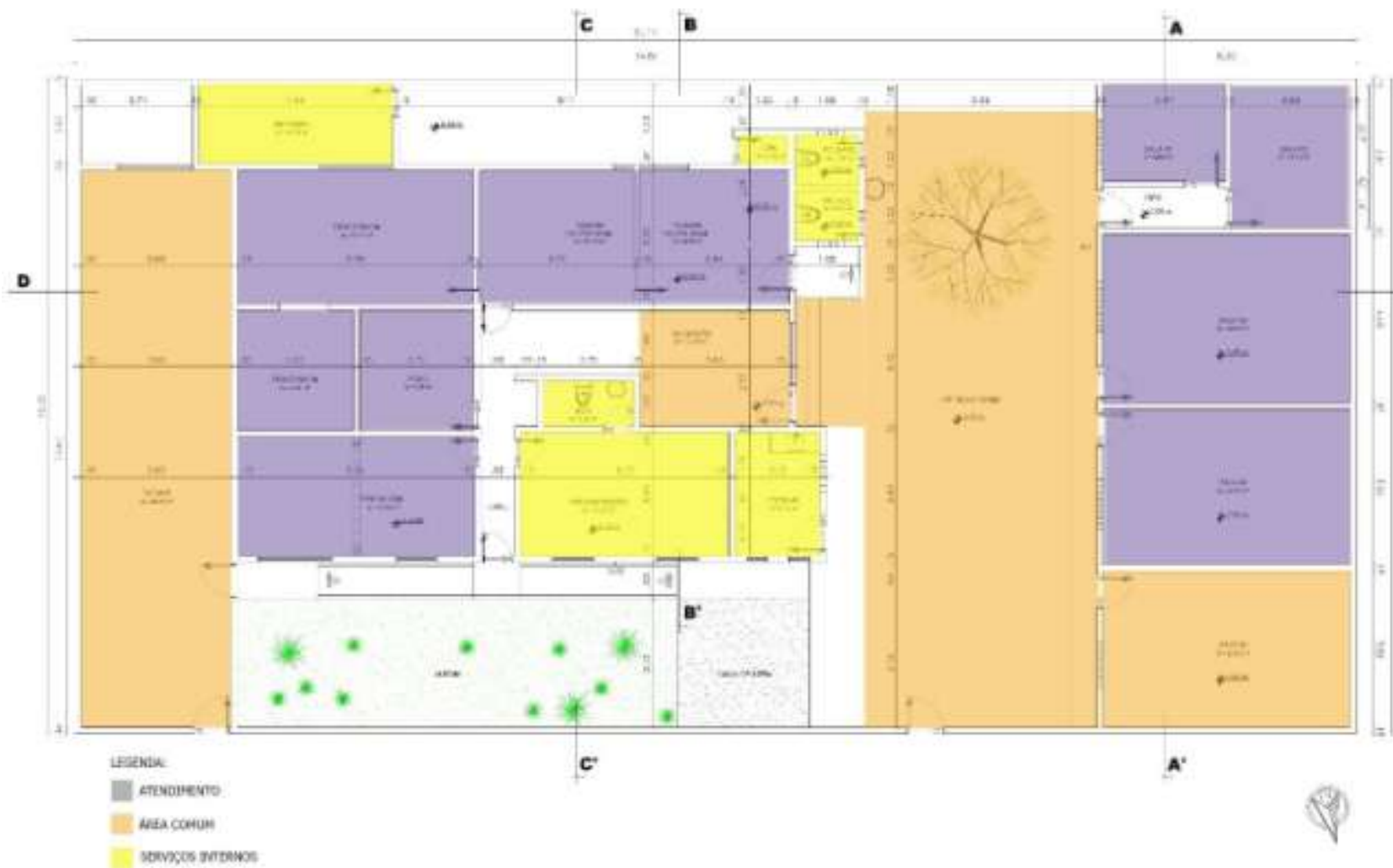

Fonte - Arquivo Pessoal, 2018.

Percebe-se que a setorização dos ambientes e o dimensionamento dos mesmos não se tornam adequado para a circulação dos diferentes fluxos diários. Pacientes, operadores de serviços, funcionários e acompanhantes acabam cruzando e congestionando os ambientes de circulação. Estes que nem sempre tem dimensões de acordo com os referenciais para deslocamento de pessoas em pé ou em cadeiras de rodas (Figura 7).

Além de dimensões inadequadas onde alguns ambientes como área de tatame e administração são superdimensionados e, outros, como salas de atendimento e banheiros são subdimensionados, o acesso a eles muitas vezes é inadequado. Um dos maiores problemas da instituição é a falta de banheiro acessíveis. Em entrevistas com os familiares dos pacientes este foi o ponto de maior questionamento por parte deles que afirmam muita dificuldade para ajudar e constrangimentos.

Os banheiros de uso público não têm dimensões adequadas conforme a norma brasileira de acessibilidade. Não garantem o posicionamento das peças sanitárias e os seguintes parâmetros de acessibilidade: circulação com o giro de 360, área necessária para garantir a transferência lateral, perpendicular e diagonal para a bacia sanitária, a área de manobra pode utilizar no máximo $0,10 \mathrm{~m}$ sob a bacia sanitária e $0,30 \mathrm{~m}$ sob o lavatório, lavatório sem coluna ou com coluna suspensa ou lavatório sobre tampo, dentro do sanitário ou boxe acessível, em local que não interfira na área de transferência para a bacia sanitária, podendo sua área de aproximação ser sobreposta à área de manobra, quando o boxe for instalado em locais de prática de esportes, as portas devem atender a um vão livre mínimo 


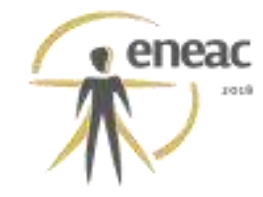

de 1,00m; alcance manual para acionamento da válvula sanitária, da torneira, das barras, puxadores e trincos e manuseio e uso dos acessórios e alcance visual do espelho (Figura 8)

\section{Figura 7 - Esquema referencial para deslocamento de pessoas a pé}

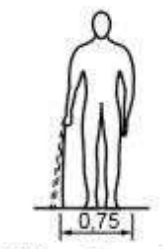

a) Uma bengala

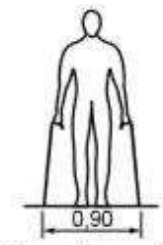

b) Duas bengalas

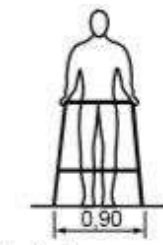

c) Andador com rodas

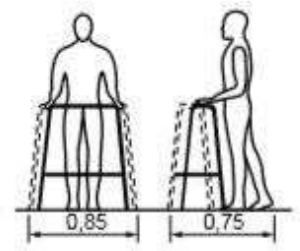

d) Andador rígido - Vistas frontal e lateral

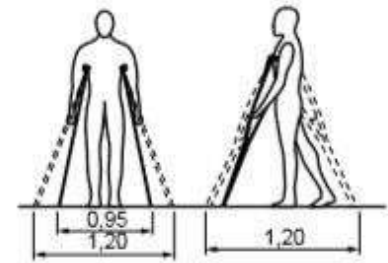

e) Muletas - Vistas frontal e lateral

Fonte - NBR 9050, 2015.

Figura 8 - Planta baixa situação atual/ Esquema medidas mínimas para sanitário acessível
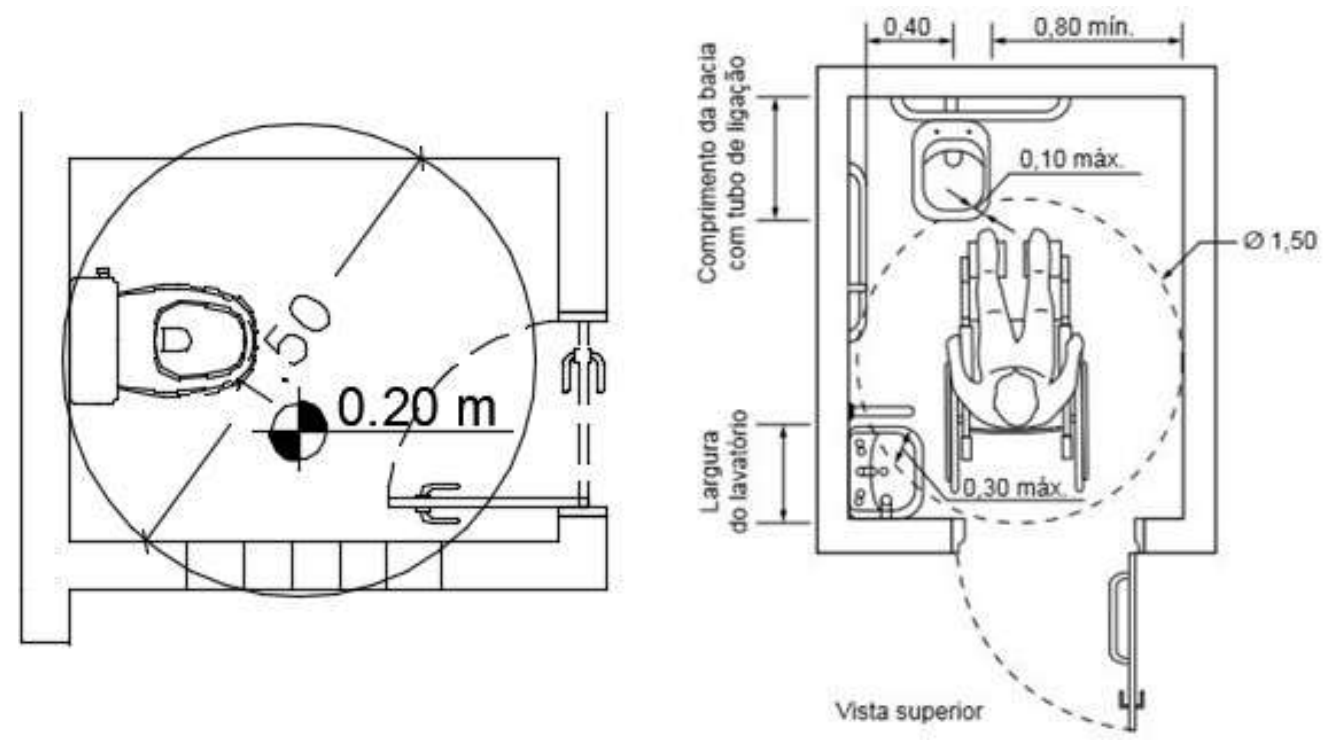


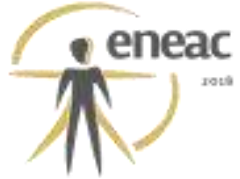

\section{A ANÁLISE DAS CONDIÇÕES DO ESPAÇO EM RELAÇÃO A ACESSIBILIDADE}

Foi constatada a necessidade de uma intervenção que proporcione qualidade ao ambiente como um todo pois, além dos problemas de acessibilidade, a estrutura precária com telhado mal feito e falta de drenagem no terreno, ambientes quentes, escuros e úmidos e a setorização desproporcional tornam o ambiente construído problemático para abrigar uma instituição voltada para a saúde. Pois conforme Villarouco e Mont'Alvão (2011) os elementos que compõe o ambiente construído a serem considerados ergonomicamente, são aqueles referentes ao conforto ambiental (lumínico, térmico e acústico), à percepção ambiental (aspectos cognitivos), adequação de materiais (revestimentos e acabamentos), cores e texturas, acessibilidade, medidas antropométricas (layout, dimensionamento), e sustentabilidade.

Neste caso, o ambiente construído como um todo não dá possibilidade e condição de alcance, percepção e entendimento para utilização, com segurança e autonomia, de espaços, informação e comunicação, bem como outros serviços de uso coletivo por pessoa com deficiência ou mobilidade reduzida conforme definição de acessibilidade apresentada na NBR 9050:2015.

A ONG CAINE e seus colaboradores exercem um trabalho muito nobre para as pessoas da região e superam todas as dificuldades financeiras e sociais para exercer suas atividades. Contudo todos os envolvidos merecem e precisam de melhores condições de uso do espaço. A condição das instituições voltadas para saúde em Jaboatão e em toda a região metropolitana do Recife precisam ser analisadas de maneira cuidadosa pois a grande maioria das instituições locais apresentam estruturas precárias e que não atendem as necessidades do público ou são inacessíveis.

\section{REFERÊNCIAS BIBLIOGRÁFICAS}

ABNT, Associação Brasileira de Normas Técnicas. NBR 9050:2015. Acessibilidade de pessoas portadoras de deficiências a edificação, espaço, mobiliário e equipamentos urbanos. Rio de Janeiro: ABNT, 2015.

SOUTO, Débora Camila Aires Cavalcante; SILVA, Daniela Madruga Rego Barros Victor. As normas de proteção a pessoa com deficiência e à acessibilidade ao metrô de Jaboatão dos Guararapes - PE.

OLIVEIRA, Luiza Maria Borges. Cartilha do Censo 2010: Pessoas com Deficiência. Brasília: SDH-PR/SNPD, 2012.

SILVA, Marco Aurélio Farias da. Você conhece os direitos da pessoa com deficiência? : perguntas e repostas / Organização Centro de Apoio às Promotorias de Defesa da Cidadania ; Marco Aurélio Farias da Silva. - Recife : Procuradoria Geral de Justiça, 2014.

OLIVEIRA, Gilberto Rangel de; MONT'ALVÃO, Claudia Renata. Metodologias utilizadas nos estudos de Ergonomia do Ambiente Construído e uma proposta de modelagem para projetos de Design de Interiores. Estudos em Design | Revista (online). Rio de Janeiro: v. 23 | n. 3 [2015], p. $150-165$. 